\title{
Simultaneous extraction and purification of alkaloids from Sophora flavescens Ait. by microwave-assisted aqueous two-phase extraction with ethanol/ammonia sulfate system
}

\author{
Wei Zhang ${ }^{\mathrm{a}}$, Dan Zhu ${ }^{\mathrm{b}}$, Huajun Fan ${ }^{\mathrm{b}, \mathrm{c}, *}$, Xiaoqin Liu ${ }^{\mathrm{b}}$, Qiang Wan ${ }^{\mathrm{b}}$, Xuehao Wu ${ }^{\mathrm{b}}$, Peng Liu ${ }^{\mathrm{c}}$, \\ James Z. Tang ${ }^{\mathrm{c}}$ \\ a School of Basic Courses, Guangdong Pharmaceutical University, Guangzhou 510006, China \\ ${ }^{\mathrm{b}}$ College of Pharmacy, Guangdong Pharmaceutical University, Guangzhou 510006, China \\ ${ }^{c}$ School of Pharmacy, Faculty of Science and Engineering, University of Wolverhampton, Wolverhampton WV1 1LY, United Kingdom
}

\section{A R T I C L E I N F O}

\section{Article history:}

Received 16 December 2013

Received in revised form 11 November 2014

Accepted 13 November 2014

Available online 6 December 2014

\section{Keywords:}

Aqueous two-phase systems

Microwave-assisted aqueous two-phase

extraction

Alkaloids

Sophora flavescens Ait.

Mechanisms

\begin{abstract}
A B S T R A C T
A rapid and effective method of integrating extraction and purification for alkaloids from Sophora flavescens Ait. was developed by microwave-assisted aqueous two-phase extraction (MAATPE) based on the high efficiency of microwave-assisted extraction (MAE) and the demixing effect of aqueous two-phase extraction (ATPE). The aqueous two-phase system (ATPS), ethanol/ammonia sulfate was chosen from seven combinations of ethanol/salt systems, and its extraction properties were investigated in detail. Key factors, namely, the compositions of ATPS, solvent-to-materials ratio, and the extraction temperature were selected for optimization of the experimental conditions using response surface methodology (RSM) on the basis of the results of the single-factor experiment. The final optimized conditions were, the compositions of ATPS: ethanol $28 \%(\mathrm{w} / \mathrm{w})$ and $\left(\mathrm{NH}_{4}\right)_{2} \mathrm{SO}_{4} 18 \%(\mathrm{w} / \mathrm{w})$, solvent-to-material ratio $60: 1$, temperature $90^{\circ} \mathrm{C}$, extraction time $5 \mathrm{~min}$, and microwave power $780 \mathrm{~W}$. MAATPE was superior to MAE, the latter using a single solvent, not only in extraction yield but also in impurity content. Moreover, compared with the combination of MAE and ATPE in the two-step mode, MAATP demonstrated fewer impurities, a better yield $(63.78 \pm 0.45 \mathrm{mg} / \mathrm{g})$ and a higher recovery $(92.09 \pm 0.14 \%)$ in the extraction and purification of alkaloids. A continuous multiphase-extraction model of MAATPE was proposed to explicate the extraction mechanism. MAATPE revealed that the interaction between microwave and ATPS cannot only cause plant cell rupture but also accelerate demixing, improving mass-transfer from solid-liquid extraction to liquidliquid purification. MAATPE simplified procedures also contributed to the lower loss occurrence, better extraction efficiency, and reduced impurity to target constituents.
\end{abstract}

() 2014 Elsevier B.V. All rights reserved.

\section{Introduction}

Sophora flavescens Ait. also named as Kushen, belongs to leguminous plant of sophora. As a typical traditional Chinese medicine, it has been commonly used for the treatment of viral hepatitis, cancer, viral myocarditis, gastrointestinal hemorrhage, and skin diseases such as eczema, colpitis, and psoriasis [1]. Alkaloids and flavonoids are reportedly the major active constituents of this plant; alkaloids, in particular, have attracted increasing attention to their high pharmacological activities, which exhibit sedative, analgesic and other central nervous system inhibition effects as well as antipyretic, anti-tumor, and anti-myocardial actions [1-16]. So far, more than 20 alkaloids have been isolated from

* Corresponding author at: College of Pharmacy, Guangdong Pharmaceutical University, Guangzhou 510006, China. the root, leaves and flowers of S. flavescens Ait. [2-6,17-20]. Oxymatrine and matrine are known as the main alkaloids in the extracts, and have been widely used as primary ingredients in pharmaceutical preparations in various forms, such as suppositories, capsules, tablets and creams [1,21-24]. Moreover, alkaloids have also been used as green pesticides in agriculture due to insecticidal effects $[25,26]$. The huge demands for alkaloids in the market drive further investigations aimed at the improvement of methods for extraction and purification.

Alkaloids in S. flavescens Ait. are usually extracted through conventional methods, such as solvent soaking extraction, heat reflux extraction, and soxhlet extraction [1,27], which are subject to remarkable shortcomings, including the lengthy process, the high cost of organic solvents, low recovery, and toxic solvent residuals in the products, etc. Various approaches, including ultrasonic, microwave, supercritical fluid and ionic liquid sorbent have been 
developed to reduce the extraction time, minimize solvent consumption, increase the extraction yield, and improve the quality of extracts [19,28-30]. Microwave-assisted extraction (MAE) becomes increasingly popular in traditional Chinese medicine for extracting the active constituents from organisms and plants due to its beneficial characteristics of quick heating, low quantity solvent used, decreased energy consumption and pollution [31-34]. It is a unique technique, in which molecules and polar bonds in the extraction medium can be agitated by microwave [35-37]. Via the interactions of microwave, the weak bonds of the target constituents to the matrix are disrupted and the solvent-to-matrix material penetration is accelerated, leading to a fast release of constituents from matrix materials.

Aqueous two-phase extraction (ATPE) was first introduced by Albertson in the separation of biomolecules. It offers an alternative to the conventional liquid-liquid extraction due to its properties, such as the high yield, the environment-friendly features, the easiness to scale-up as well as lower costs and the diminished damage to the biological activity of molecules [38]. ATPE has been widely applied in the recovery and purification of biomolecules, including proteins, enzymes, and antibiotics [39-43]. The success of ATPE is largely dependent on the selection of the aqueous two-phase system (ATPS), which is usually composed of two or more phaseforming substances in water (e.g., two different polymers, a polymer and a salt, two or more different surfactants). However, most phase-forming polymers and surfactants are too viscous to process, and difficult to form transparent solutions. Recent investigations have shifted the paradigm from fragile biomolecules to small molecules in natural products. The ATPS is moderated by a short-chain alcohol and salt solution. It offers the advantages of low viscosity, easy demixing, solvent recycling, a more environment-friendly process, and the gained larger popularity in extracting the active constituents from medicinal plants [44-50].

The combination of microwave with extraction has advantages in achieving high yields in the reactions, in which polar solvents such as methanol, ethanol and water were used $[51,28]$. However, MAE recovers also more impurities, resulting in a more complicated sample pretreatment for qualitative and quantitative analyses. In our recent investigation, ATPE was used for purification after MAE [52]. The recovery of the alkaloids was in the range from $91.03 \%$ to $94.46 \%$. ATPSs had a high electric constant, and could be integrated with MAE, forming an innovative technique named microwave-assisted aqueous two-phase extraction (MAATPE). It is a one-step extraction, a new, potential, and powerful alternative to the conventional extraction. Only limited publications have described so far [53-57].

In this paper, a rapid and effective method for extraction and purification of alkaloids from S. flavescens Ait. was introduced, which was developed by integrating MAE with ATPE through optimizing the ATPS system and MAATPE extraction process. The ATPS optimization was done in depicting a broad phase diagram, acquiring the composition window of ATPS in consideration of the phase ratio $\alpha$ in a 3-D fashion. The MAATPE extraction process was investigated using single-factor experiment and response surface methodology (RSM). Several key factors, namely, the compositions of ATPS, solvent-to-materials ratio, and the extraction temperature were selected for RSM studies in terms of the results of the single factor experiment. Responses concerning the yield and recovery of alkaloids were evaluated. In order to better understand the disruption effect on matrix materials during extraction, the morphologies of matrix materials were observed under scanning electron microscope (SEM) immediately after extraction and compared with those from other extraction methods. To evaluate the extraction efficiency, the results of MAATPE were juxtaposed with a two-step method combining MAE extraction by using water or ethanol, with ATPE purification. It was found that the results of MAATPE were equally satisfying, and its operational process was easier and more efficient. To the best of our knowledge, this is the first application of a novel MAATPE in the extraction of alkaloids from S. flavescens Ait.

\section{Experimental}

\subsection{Materials and reagents}

Dried roots of $S$. flavescens Ait., which were collected from Shanxi Province in China, were purchased from a local drug store of Guangzhou (Local identified number 20090901). The samples were powdered, sieved (20-120 mesh), and placed in a desiccator. The matrix sample materials were kept in a dark place, placed in desiccators and stored in a closed cupboard at room temperature until used.

Oxymatrine and matrine (purities were $\geqslant 98.0 \%$ ) were purchased from Xi'an Xuhuang Bio-Tech Co., Ltd (China). N-oxysophocarpine, sophocarpine and sophoridine (purities $\geqslant 98.0 \%$ ) were bought from Nanjing Zelang pharmaceutical science and technology Co., Ltd. (China). Methanol and acetonitrile of HPLC grade were obtained from Merck Darmstadt Ltd. (Germany). All other chemicals were analytical grade (Guangzhou Chemical Reagent Factory, China).

\subsection{Instruments and apparatus}

All extraction experiments were performed on an EXCEL microwave extraction system (PreeKem Scientific Instruments Co., Ltd. China) equipped with a digital timer, power and a temperature controller. HPLC analysis was carried out using Agilent 1200 Infinity chromatograph (Agilent Technologies Co., Ltd. USA).

\subsection{Plotting phase diagram of ATPS}

The phase diagram was determined by turbidity titration method. A certain amounts of salt $\left(\left(\mathrm{NH}_{4}\right)_{2} \mathrm{SO}_{4}\right.$, or $\left.\mathrm{K}_{2} \mathrm{HPO}_{4}\right)$ were added into a dozens of tubes containing deionized water, respectively. Ethanol was subsequently added dropwise into each tube until the solution became turbid. The point at which the solution first became turbid was designated as the turbid point and the quantity of added ethanol was recorded. The phase diagram was plotted according to different ethanol concentrations versus ammonium sulfate concentrations at different turbid points.

\subsection{The preparation of ATPS}

ATPSs were prepared according to the phase diagram plotted by Xiaoqin Liu et al. [52]. Each of the salts tested (ammonium sulfate, dipotassium hydrogen phosphate, sodium carbonate, sodium sulfate, calcium chloride, potassium dihydrogen phosphate or sodium chloride) was dissolved in deionized water, respectively. The salt solution was mixed with ethanol by a vortex stirrer. ATPS was formed when the mixture showed two phase separation at the cloud point. The phase ratio $(\alpha)$ was calculated by measuring the volumes of top ( $\left.V_{\text {top }}\right)$ and bottom $\left(V_{\text {bottom }}\right)$ phases.

$$
\alpha=\frac{V_{\text {top }}}{V_{\text {bottom }}}
$$

\subsection{MAATPE procedure}

Each sample ( $0.5 \mathrm{~g}$ sieved by 80 -mesh) and ATPS ( $30 \mathrm{~mL}$ ) were put into an extraction vessel, which was then sealed and placed in the microwave extraction system. The extraction was conducted at 
$90{ }^{\circ} \mathrm{C}$ under $780 \mathrm{~W}$ for $5 \mathrm{~min}$. After cooling in the oven, the extract was filtered to remove the solid residue. The filtrate was further separated into two phases. The top and bottom phases were collected separately. The residues were obtained after removal of the solvent by a controlled evaporation. For HPLC analysis, the obtained residues were dissolved in methanol and diluted up to $50 \mathrm{~mL}$. The extraction was assessed by the yield $(Y)$ and recovery $(R)$ of alkaloids, which were calculated as follows:

Yield $(\mathrm{mg} / \mathrm{g})=\frac{m_{e}}{m}$

Recovery $(\%)=\frac{m_{T}}{m_{T}+m_{B}} \times 100 \%$

where $m_{e}$ is the total quantity of alkaloids extracted from the plant material $(m) ; m_{T}$ is the quantity of alkaloids extracted in the top phase, and $m_{B}$ is the quantity of alkaloids in the bottom phase.

\subsection{HPLC analysis}

The concentrations of alkaloids in the extracts were determined by HPLC with a UV detector at $220.0 \mathrm{~nm}$ using a Phenomenex Geminin $\mathrm{C}_{18}$ Column $(5 \mu \mathrm{m}, 250 \mathrm{~mm} \times 4.6 \mathrm{~mm})$ as the stationary phase. The mobile phase was made of methanol (A), acetonitrile (B) and $0.1 \%(\mathrm{w} / \mathrm{v})$ ammonia solution $(\mathrm{pH}=10.3)(\mathrm{C})$. Alkaloids were eluted at $30{ }^{\circ} \mathrm{C}$ in the following gradient mode: $0-6$ min: 8.5-9.0\% A, 9.5-9.0\% B and 82\% C; 6-11 min: 9.0-16.0\% A, 9.016.0\% $\mathrm{B}$ and $82.0-68.0 \% \mathrm{C} ; 11-45 \mathrm{~min}: 16.0 \% \mathrm{~A}, 16.0 \% \mathrm{~B}$, and $68.0 \% \mathrm{C}$. The injection volume was $20 \mu \mathrm{L}$. The flow rate was $1.0 \mathrm{~mL} / \mathrm{min}$.

\subsection{Experimental design and statistical analysis}

A four-variable, three-level central composite design (CCD) was applied to determine the best combination of the extraction variables for the yield and recovery of alkaloids from $S$. flavescens Ait. The range and center point values of four independent variables (Table 4) were based on the results of single-factor experiments. The response to the design experiment is given in Table 5. All data were determined by HPLC in triplicate, and the results were averaged. The Design-Expert software version 8.0 was employed for the regression analysis and the optimization.

Experimental data were fitted to a quadratic polynomial model and the model was explained by the following quadratic equation:

$Y=\beta_{0}+\sum_{i=1}^{3} \beta_{i} X_{i}+\sum_{i=1}^{3} \beta_{i i} X_{i}^{2}+\sum_{i=1}^{3} \sum_{j=i+1}^{3} \beta_{i j} X_{i} X_{j}$

where $X_{i}, X_{j}$ are the input variables, which influence the response function $Y ; \beta_{0}$ is the intercept; $\beta_{i}, \beta_{i i}$, and $\beta_{i j}$ are the coefficients of the linear, quadratic, and the interaction term, respectively.

\section{Table 4}

Independent variables and their levels for central composite design.

\begin{tabular}{|c|c|c|c|}
\hline \multirow[t]{2}{*}{ Variables } & \multicolumn{3}{|c|}{ Factor level } \\
\hline & -1 & 0 & 1 \\
\hline$X_{1} /$ Ethanol concentration (\%) & 22 & 25 & 28 \\
\hline$X_{2} /$ Ammonium sulfate $(\%)$ & 18 & 20 & 22 \\
\hline$X_{3} /$ Solvent-to-material ratio (mL:g) & $40: 1$ & $50: 1$ & $60: 1$ \\
\hline $\mathrm{X}_{4} /$ Extraction temperature $\left({ }^{\circ} \mathrm{C}\right)$ & 90 & 100 & 110 \\
\hline
\end{tabular}

Table 1

The formation and property of ATPSs [52].

\begin{tabular}{|c|c|c|c|}
\hline Phase composition & & Phase demixing & Formation feature \\
\hline \multirow{7}{*}{ Ethanol } & $\left(\mathrm{NH}_{4}\right)_{2} \mathrm{SO}_{4}$ & Quick & Easy, stable, and transparent \\
\hline & $\mathrm{K}_{2} \mathrm{HPO}_{4}$ & Quick & Easy, stable, and transparent \\
\hline & $\mathrm{Na}_{2} \mathrm{CO}_{3}$ & Slow & Stable, turbid in top phase \\
\hline & $\mathrm{Na}_{2} \mathrm{SO}_{4}$ & Quick & Unstable, precipitation in bottom phase \\
\hline & $\mathrm{CaCl}_{2}$ & No & Difficult \\
\hline & $\mathrm{KH}_{2} \mathrm{PO}_{4}$ & No & Difficult \\
\hline & $\mathrm{NaCl}$ & No & Difficult \\
\hline
\end{tabular}

Table 2

The effect of the concentration of ethanol on extraction of alkaloids.

\begin{tabular}{|c|c|c|c|c|c|c|c|c|}
\hline \multirow[t]{2}{*}{$C_{\mathrm{EtOH}}(\%)$} & \multirow[t]{2}{*}{$C_{(\mathrm{NH} 4) 2 \mathrm{SO} 4}(\%)$} & \multirow[t]{2}{*}{$\Delta \kappa\left(10^{4}\right)^{*}(\mathrm{~s} / \mathrm{cm})$} & \multirow[t]{2}{*}{ Demixing time (s) } & \multirow[t]{2}{*}{ Phase ratio $\alpha$} & \multicolumn{2}{|l|}{ Yield (mg/g) } & \multicolumn{2}{|l|}{ Recovery (\%) } \\
\hline & & & & & Oxymatrine & Total alkaloids** & Oxymatrine & Total alkaloids** \\
\hline 20 & 20 & 48.44 & 137 & 0.48 & 3.17 & 45.42 & 14.17 & 21.91 \\
\hline 22 & 20 & 54.64 & 66 & 0.72 & 14.50 & 48.69 & 67.09 & 76.10 \\
\hline 25 & 20 & 60.16 & 40 & 0.94 & 20.47 & 61.91 & 85.18 & 90.43 \\
\hline 28 & 20 & 64.14 & 23 & 1.16 & 18.47 & 54.63 & 87.11 & 91.58 \\
\hline 30 & 20 & 85.48 & 15 & 1.38 & 17.35 & 47.1 & 91.17 & 93.74 \\
\hline
\end{tabular}

* $\Delta k$ here is the conductivity difference between the top and bottom phases.

** It represents total alkaloids, including oxymatrine. Their meaning is same as Table 3.

Table 3

The effect of the concentration of $\left(\mathrm{NH}_{4}\right)_{2} \mathrm{SO}_{4}$ on extraction of alkaloids.

\begin{tabular}{|c|c|c|c|c|c|c|c|c|}
\hline \multirow[t]{2}{*}{$C_{(\mathrm{NH} 4) 2 \mathrm{SO} 4}(\%)$} & \multirow[t]{2}{*}{$C_{\text {EtOH }}(\%)$} & \multirow[t]{2}{*}{$\Delta \kappa\left(10^{4}\right)^{\mathrm{a}}(\mathrm{s} / \mathrm{cm})$} & \multirow[t]{2}{*}{ Demixing time (s) } & \multirow[t]{2}{*}{ Phase ratio $\alpha$} & \multicolumn{2}{|l|}{ Yield (mg/g) } & \multicolumn{2}{|l|}{ Recovery (\%) } \\
\hline & & & & & Oxymatrine & Total alkaloids ${ }^{\mathrm{b}}$ & Oxymatrine & Total alkaloids ${ }^{\mathrm{b}}$ \\
\hline 18 & 25 & 58.15 & 64 & 1.05 & 13.47 & 50.70 & 68.52 & 73.39 \\
\hline 20 & 25 & 59.42 & 41 & 0.95 & 17.81 & 60.45 & 80.63 & 88.72 \\
\hline 22 & 25 & 61.18 & 33 & 0.82 & 16.98 & 58.95 & 80.82 & 88.41 \\
\hline 24 & 25 & 63.08 & 32 & 0.63 & 16.31 & 53.96 & 80.07 & 82.02 \\
\hline
\end{tabular}

a $\Delta k$ here is the conductivity difference between the top and bottom phases.

b It represents total alkaloids, including oxymatrine, N-oxysophocarpine, sophoridine, matrine and sophocarpine. 
Table 5

Analysis of variance (ANOVA) for response surface model of the extraction yield of total alkaloids.

\begin{tabular}{|c|c|c|c|c|c|c|}
\hline Source & Sum of squares & $d_{f}$ & Mean square & $F$ value & $P$-value & Significant $^{\mathrm{a}}$ \\
\hline Model & 4157.60 & 15 & 277.17 & 214.43 & $<0.0001$ & +++ \\
\hline$X_{1}$ & 278.50 & 1 & 278.50 & 215.45 & $<0.0001$ & +++ \\
\hline$X_{2}$ & 24.15 & 1 & 24.15 & 18.68 & 0.0010 & ++ \\
\hline$X_{3}$ & 4.06 & 1 & 4.06 & 3.14 & 0.1018 & - \\
\hline$X_{4}$ & 47.63 & 1 & 47.63 & 36.85 & $<0.0001$ & +++ \\
\hline$X_{1} X_{2}$ & 777.54 & 1 & 777.54 & 598.43 & $<0.0001$ & +++ \\
\hline$X_{1} X_{3}$ & 2.71 & 1 & 2.71 & 2.09 & 0.1736 & - \\
\hline$X_{1} X_{4}$ & 16.87 & 1 & 16.87 & 13.05 & 0.0036 & ++ \\
\hline$X_{2} X_{3}$ & 1.02 & 1 & 1.02 & 0.78 & 0.9780 & - \\
\hline$X_{2} X_{4}$ & 1.44 & 1 & 1.44 & 0.96 & 0.3422 & - \\
\hline$X_{3} X_{4}$ & 2.04 & 1 & 2.04 & 1.21 & 0.2895 & - \\
\hline$X_{1}^{2}$ & 99.22 & 1 & 99.22 & 76.76 & $<0.0001$ & +++ \\
\hline$X_{2}^{2}$ & 57.63 & 1 & 57.63 & 44.58 & $<0.0001$ & +++ \\
\hline$X_{3}^{2}$ & 23.46 & 1 & 23.46 & 18.29 & 0.0012 & ++ \\
\hline$X_{4}^{2}$ & 49.84 & 1 & 49.84 & 38.21 & $<0.0001$ & +++ \\
\hline Residual & 15.51 & 12 & 1.29 & & & \\
\hline Lack of fit & 12.86 & 7 & 1.84 & 3.47 & 0.0950 & - \\
\hline Pure error & 2.65 & 5 & 0.53 & & & \\
\hline Cor total & 4173.11 & 27 & & & & \\
\hline
\end{tabular}

a +++ , most significant $(P<0.001)$; ++, more significant $(P<0.01)$; +, significant $(P<0.05)$; - , less significant $(P>0.05)$.

\subsection{Scanning electron microscope (SEM)}

The surface micro-structures of the herb powder were observed after extraction through a Zeiss EVO 18 scanning electron microscopy (Zeiss, German). The powder was coated with gold using a SBC-12 Ion Sputtering Coater (Beijing, China). The coated sample was placed in the vacuum chamber of Zeiss EVO 18 and viewed at a voltage of $10.0 \mathrm{kV}$.

\section{Results and discussion}

\subsection{Screening of the ATPS}

Seven ATPSs were made of ethanol, water, and salts such as $\left(\mathrm{NH}_{4}\right)_{2} \mathrm{SO}_{4}, \mathrm{~K}_{2} \mathrm{HPO}_{4}, \mathrm{Na}_{2} \mathrm{CO}_{3}, \mathrm{CaCl}_{2}, \mathrm{Na}_{2} \mathrm{SO}_{4}, \mathrm{NaCl}$, and $\mathrm{KH}_{2} \mathrm{PO}_{4}$. The system was evaluated for the phase demixing and formation features. As shown in Table 1, The ATPSs made of ethanol/ $\mathrm{K}_{2} \mathrm{HPO}_{4}$, ethanol $/\left(\mathrm{NH}_{4}\right)_{2} \mathrm{SO}_{4}$, and ethanol $/ \mathrm{Na}_{2} \mathrm{SO}_{4}$ were easy to form, followed by quick phase demixing. ATPS made of ethanol/ $\mathrm{Na}_{2} \mathrm{SO}_{4}$ was excluded due to the bottom phase precipitation.

\subsection{Phase diagrams of the selected ATPSs}

The two ATPSs made of ethanol $/ \mathrm{K}_{2} \mathrm{HPO}_{4}$ and ethanol $/\left(\mathrm{NH}_{4}\right)_{2} \mathrm{SO}_{4}$ were further investigated in their phase diagrams, which were depicted based on the cloud point titration. As shown in Fig. 1, there were two zones which were delineated by a curve for tha$\mathrm{nol} /\left(\mathrm{NH}_{4}\right)_{2} \mathrm{SO}_{4}$ or ethanol $/ \mathrm{K}_{2} \mathrm{HPO}_{4}$ systems. Above the curve, there was the two-phase zone. In this zone, the top phase was the ethanol-rich aqueous phase and the bottom phase was the salt-rich phase. The results in Fig. 1 showed that the upper limit of the concentration of a salt solution was approximately $40 \%(\mathrm{w} / \mathrm{w})$ for both ATPSs and those of ethanol were approximately $50 \%(\mathrm{w} / \mathrm{w})$ for ATPS (ethanol $/ \mathrm{K}_{2} \mathrm{HPO}_{4}$ ) and $60 \%(\mathrm{w} / \mathrm{w})$ for ATPS (ethanol $/\left(\mathrm{NH}_{4}\right)_{2}$ $\mathrm{SO}_{4}$ ), respectively. The conclusions were similar to those published in recent investigations $[56,45]$.

\subsection{Comparison of the ATPSs}

ATPSs from ethanol $/ \mathrm{K}_{2} \mathrm{HPO}_{4}$ and ethanol $/\left(\mathrm{NH}_{4}\right)_{2} \mathrm{SO}_{4}$ were used in extraction of oxymatrine and matrine. The results determined by HPLC reveal that alkaloids distributed in the ethanol-rich top phase but the salt-rich bottom phase. In the comparison, shown

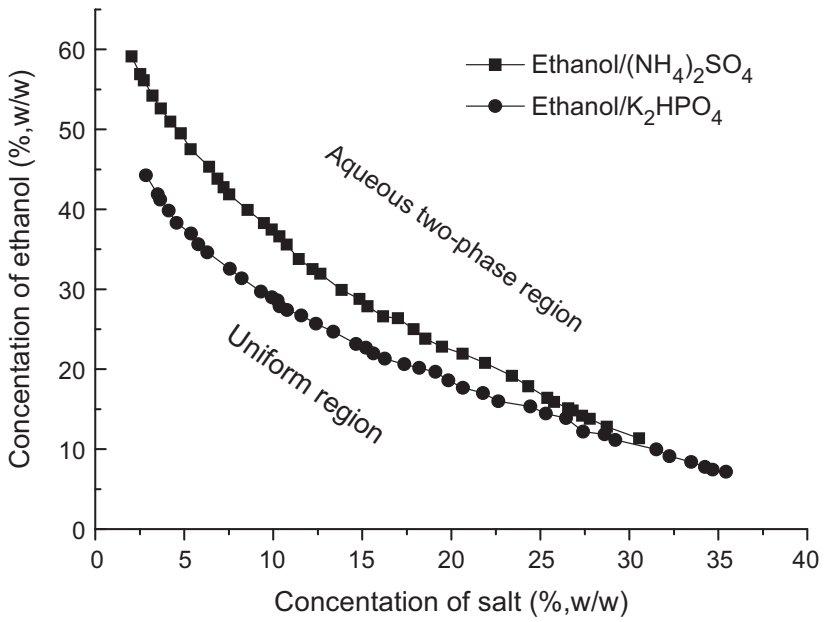

Fig. 1. The phase diagrams of ethanol $/\left(\mathrm{NH}_{4}\right)_{2} \mathrm{SO}_{4}$ and ethanol $/ \mathrm{K}_{2} \mathrm{HPO}_{4}$ systems at room temperature.

in Fig. 2, ATPS from ethanol/( $\left.\mathrm{NH}_{4}\right)_{2} \mathrm{SO}_{4}$ had better performance in extraction. Results showed that ATPS from ethanol $/\left(\mathrm{NH}_{4}\right)_{2} \mathrm{SO}_{4}$ had better recovery $(R)$ than that those from ethanol $/ \mathrm{K}_{2} \mathrm{HPO}_{4}$. Partition coefficients $(K)$ of both oxymatrine and matrine in ATPS from ethanol $/\left(\mathrm{NH}_{4}\right)_{2} \mathrm{SO}_{4}$ were higher than those from ethanol $/ \mathrm{K}_{2} \mathrm{HPO}_{4}$. Moreover, ATPS from ethanol/( $\left.\mathrm{NH}_{4}\right)_{2} \mathrm{SO}_{4}$ presented a smaller phase ratio $\alpha$, which was beneficial for the further extraction and enrichment of alkaloids by MAATPE mentioned below. Similar findings were reported in extraction of lignans [50].

The partition coefficient $(K)$ of the target compound (oxymatrine and matrine) was calculated using the following equation:

$K=\frac{C_{T}}{C_{B}}$

where $C_{T}$ and $C_{B}$ were the equilibrium concentrations of alkaloids extracted in the top phase and bottom phase, respectively.

\subsection{Study of the formation of aqueous two-phase region}

The study of the formation of the aqueous two-phase region could provide information for further optimization of the ATPS compositions for MAATPE. A moderated phase diagram of 

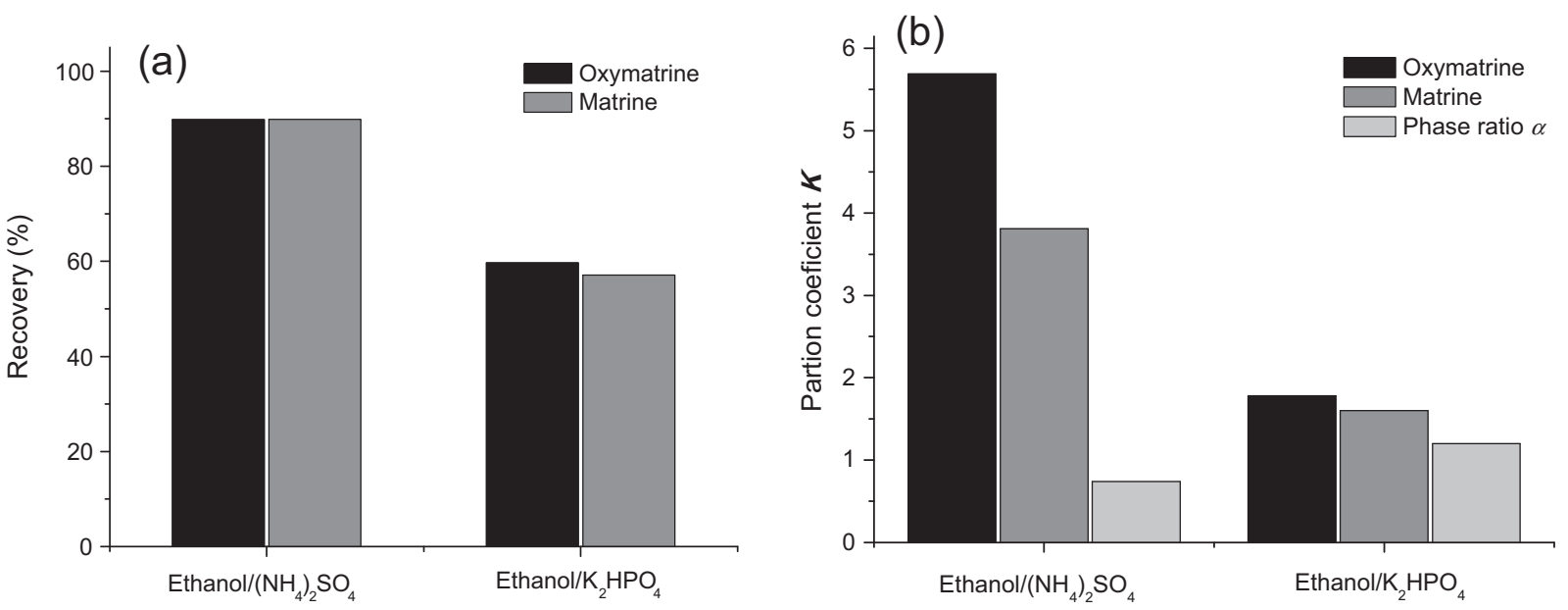

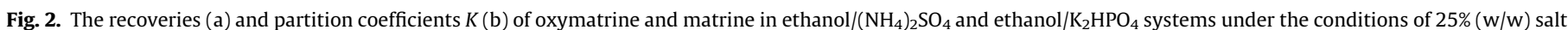
and $25 \%$ ethanol\% $(\mathrm{w} / \mathrm{w})$ at room temperature.

ethanol $/\left(\mathrm{NH}_{4}\right)_{2} \mathrm{SO}_{4}$ was depicted (Fig. 3a), based on the cloud and saturation curves. In this phase diagram, a clear aqueous twophase region was illustrated in comparison to other two regions, namely, the single-phase region and the saturation region. The turning point between the single-phase and the aqueous twophase region was determined at the cloud point. The turning point from the aqueous two-phase to the saturation region was recorded when salt precipitation was observed. The collective data indicated that ethanol concentrations from $11.4 \%(\mathrm{w} / \mathrm{w})$ to $54.1 \%(\mathrm{w} / \mathrm{w})$ and $\left(\mathrm{NH}_{4}\right)_{2} \mathrm{SO}_{4}$ concentrations from $2.1 \%(\mathrm{w} / \mathrm{w})$ to $30.6 \%(\mathrm{w} / \mathrm{w})$ were suitable for extraction.

In the combination of phase ratio $\alpha$, better ATPS could be identified for MAATPE. Our recent investigation indicated that the recovery $(R)$ was not the only response to the selection of ATPE [52]. When ATPS with ethanol concentration of $38 \%(\mathrm{w} / \mathrm{w})$ and $\left(\mathrm{NH}_{4}\right)_{2} \mathrm{SO}_{4}$ concentration of $18 \%(\mathrm{w} / \mathrm{w})$ was used for MAATPE, the phase ratio $\alpha$ was too high to acquire phase separation under the presence of herb material. After adjustment of the concentrations of ethanol and $\left(\mathrm{NH}_{4}\right)_{2} \mathrm{SO}_{4}$, ATPS, having a smaller phase ratio $\alpha$, a better extraction and enrichment could be achieved as well as a reduced usage of ethanol and operational easiness. For this reason, a 3D diagram was drawn (Fig. 3b) by adding the phase ratio $\alpha$ as the $z$-axis, projecting out from Fig. 3(a). Fig. 3(b) showed that the phase ratio $\alpha$ was strongly dependent on the compositions of ATPS. The findings of the extraction experiment showed that ATPS revealed a phase ratio $\alpha$ in the region of $0.7-1.2$, which was easier for the subsequent operations (e.g. demixing among top, herb, and bottom phases, collection respective phases, filtration, etc.) after MAATPE.

In summary, due to its better extraction properties, such as the broader range of ATPS formation, the more suitable phase ratio $\alpha$, the higher ability of recovery, and the greater partition coefficient compared to other ATPSs, the ethanol $/\left(\mathrm{NH}_{4}\right)_{2} \mathrm{SO}_{4}$ system as a solvent for extraction of alkaloids is more adaptable to MAATPE application in further investigations.

\subsection{Optimization of MAATPE conditions}

\subsubsection{Optimization of compositions of the ATPS}

In conducting a systematical study of ATPS, based on the guidance of the phase ratio $\alpha$ mentioned above, it was revealed that a broad band of ATPS compositions was found at an ethanol concentration of $20-30 \%(\mathrm{w} / \mathrm{w})$ and $\left(\mathrm{NH}_{4}\right)_{2} \mathrm{SO}_{4}$ concentration of $18-24 \%$ $(\mathrm{w} / \mathrm{w})$. A single-factor experiment was carried out and the results
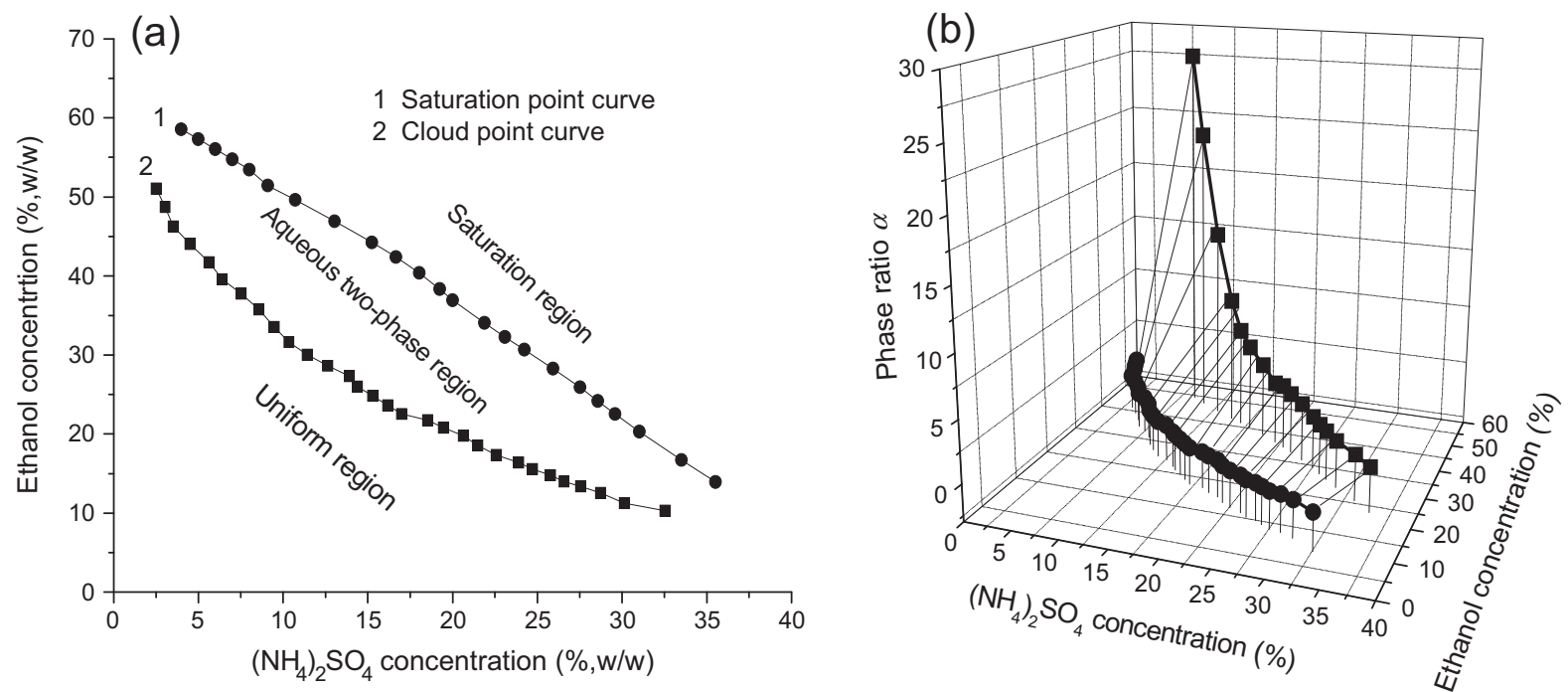

Fig. 3. The phase diagram of ethanol $/\left(\mathrm{NH}_{4}\right)_{2} \mathrm{SO}_{4}$ (a) and its distribution of phase ratio $\alpha$ (b) at room temperature. 
were presented in Table 2 and 3. The ethanol concentration of $25 \%$ was selected due to the high yield and relatively high recovery in the extraction of oxymatrine and total alkaloids. This selection also exhibited a phase ration $\alpha$ in the middle region, with a relatively faster demixing time. Similarly, the $\left(\mathrm{NH}_{4}\right)_{2} \mathrm{SO}_{4}$ concentration of $20 \%(\mathrm{w} / \mathrm{w})$ was selected, which is consistent with the results of the phase ration $\alpha$ and demixing time.

\subsubsection{Optimization of particle sizes and of solvent-to-material ratio}

Fig. 4 shows the effect of particle sizes on the yield and recovery of oxymatrine and total alkaloids. Dry herb ground to the size of mesh number 80 was suitable for MAATPE, and the extraction displayed high yield and recovery. Fig. 5 shows the effect of solventto-materials ratio on the yield and recovery of oxymatrine and total alkaloids. A high yield of the extraction was found in the solvent-to-materials ratio of 50:1 and high recovery in 20-60:1, so the solvent-to-materials ratio in this study was set at 50:1.

\subsubsection{The effect of microwave power and extraction temperature}

Fig. 6 shows the effect of the microwave power on the yield and recovery of oxymatrine and total alkaloids. The high yield and recovery were achieved at the power of $780 \mathrm{~W}$. However, the effect of the microwave power on the yield and recovery was not that significant in practical terms.
As Fig. 7 illustrates, a high yield and a relatively high recovery of oxymatrine and total were found at $100{ }^{\circ} \mathrm{C}$. Higher temperature (above $100^{\circ} \mathrm{C}$ ) caused a significant decrease of the yield of total alkaloids due to changes in chemical stability, highlighting the particular susceptibility of oxymatrine to high temperatures [58].

\subsubsection{The effect of extraction time}

Fig. 8 shows the effect of the extraction time on the yield and recovery of oxymatrine and total alkaloids. It was interesting that the high yield of total alkaloids and the high recovery of oxymatrine were found at the duration of $5 \mathrm{~min}$. The yield of oxymatrine and the recovery of total alkaloids appeared comparatively stable during the extraction time window.

\subsection{Optimization of MAATPE conditions with RSM}

The results of the single-factor experiment could be summarized as follows: ethanol, $25 \%(\mathrm{w} / \mathrm{w})$ and $\left(\mathrm{NH}_{4}\right)_{2} \mathrm{SO}_{4}, 20 \%(\mathrm{w} / \mathrm{w})$; the size of matrix materials 80 mesh; the solvent-to-materials ratio of $50: 1$; the microwave power, $780 \mathrm{~W}$; the extraction temperature, $100^{\circ} \mathrm{C}$; and the extraction time of $5 \mathrm{~min}$. Among these conditions, ATPS compositions chosen were in line with the pre-determined scales. They were variables interrelated in the extraction and needed further RSM verification. The solvent-tomaterials ratio was fixed close to the top scale, leaving room for
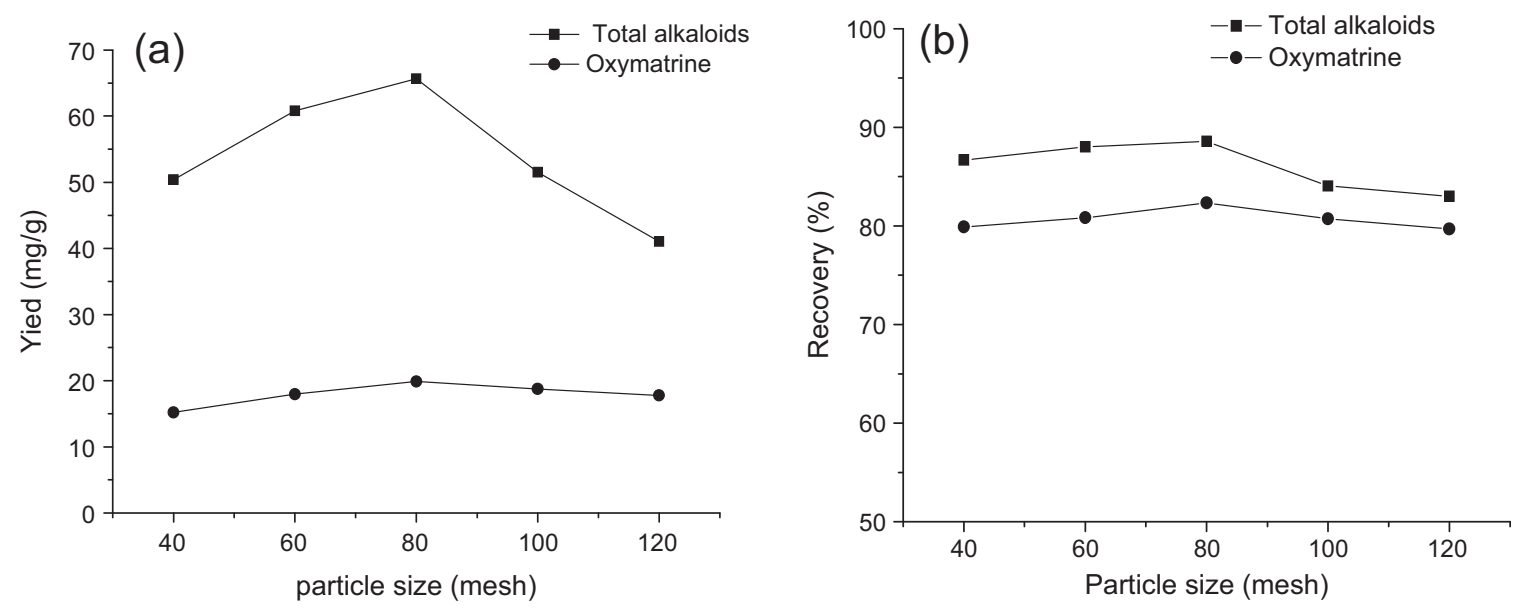

Fig. 4. The effect of the particle size on the yield (a) and recovery (b) of oxymatrine and total alkaloids.
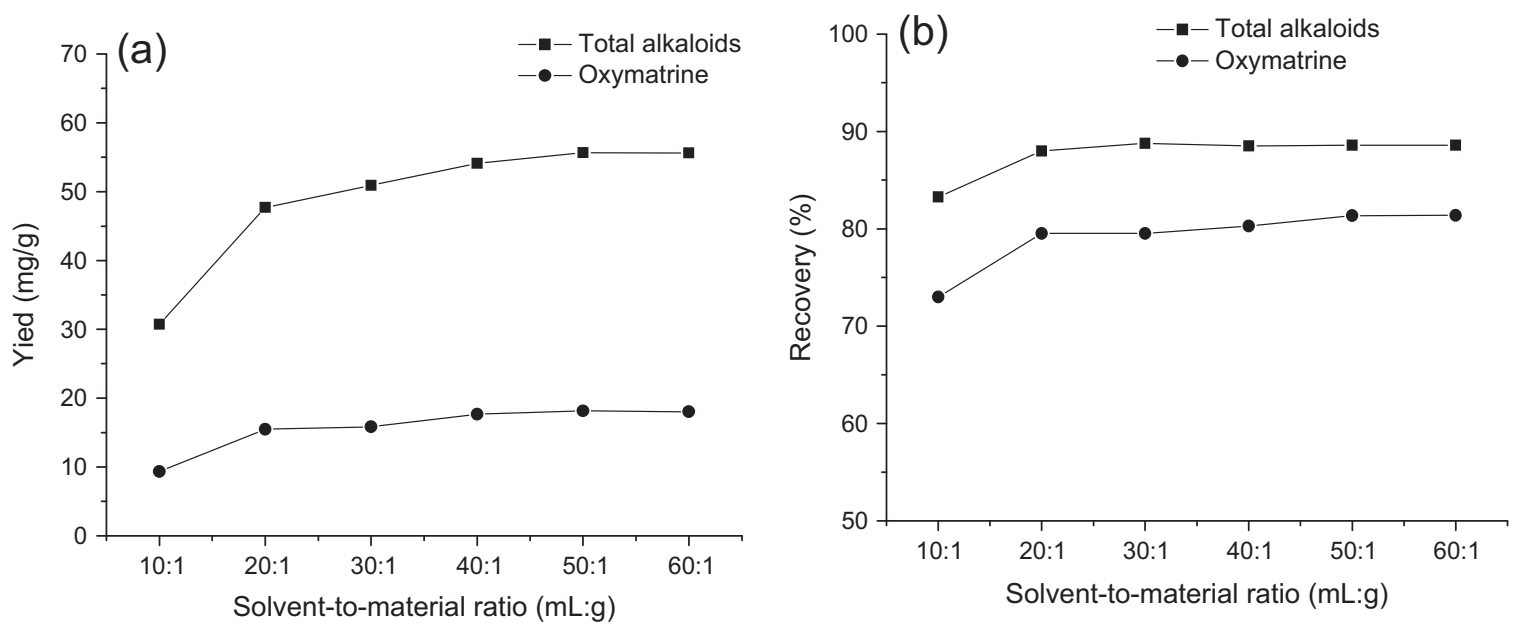

Fig. 5. The effect of solvent-to-material ratio on the yield (a) and recovery (b) of oxymatrine and total alkaloids. 

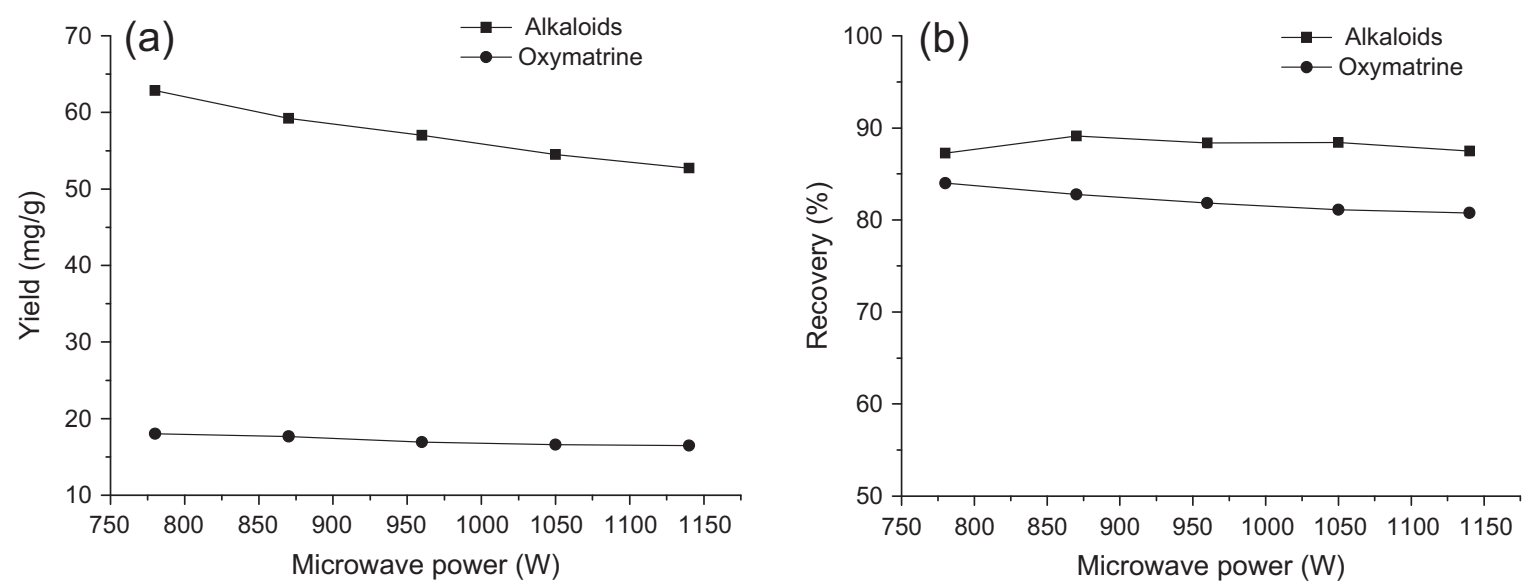

Fig. 6. The effect of microwave power on the yield (a) and recovery (b) of oxymatrine and total alkaloids.
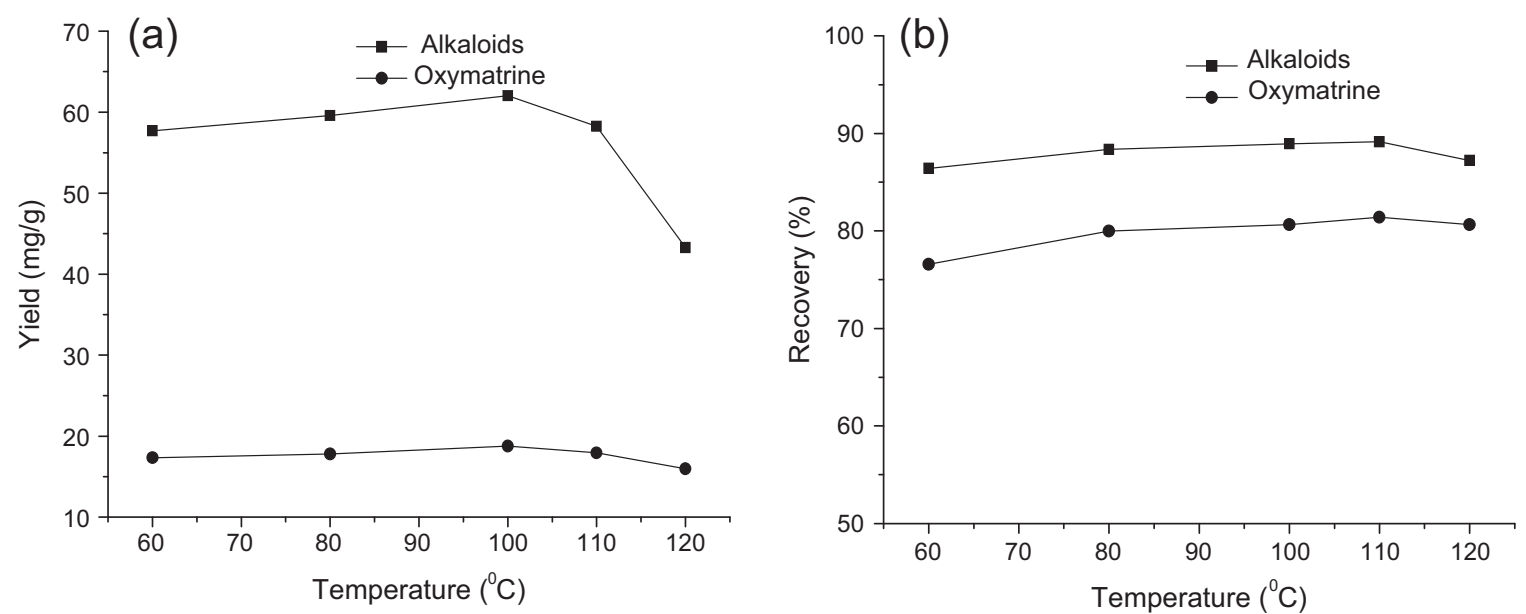

Fig. 7. The effect of extraction temperature on the yield (a) and recovery (b) of oxymatrine and total alkaloids.
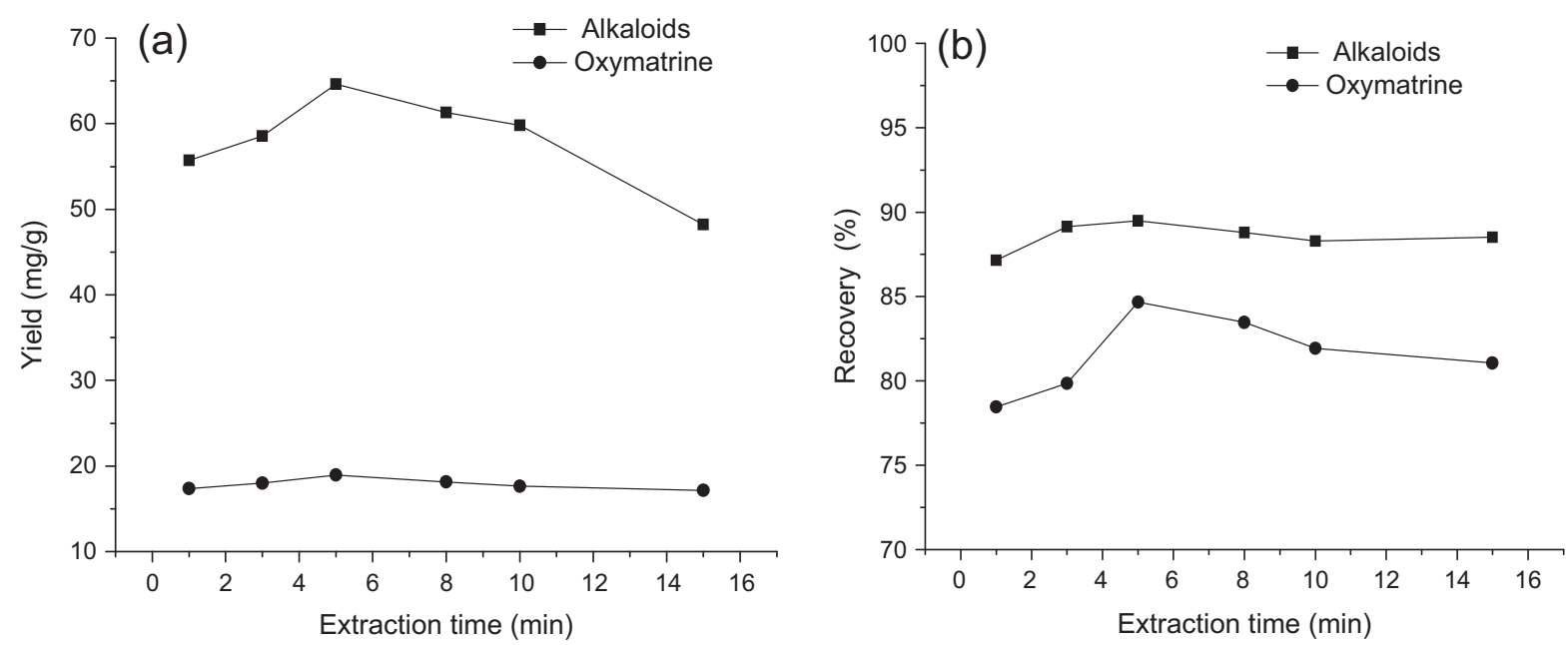

Fig. 8. The effect of extraction time on the yield (a) and recovery (b) of oxymatrine and alkaloids.

improvement. Microwave power input, i.e. the extraction temperature caused unstable loss of ingredients in the extract [58]; hence, it deserves a further analysis. According to central composite design (CCD), shown in Table 4, the RSM was introduced to determine the best combination of extraction variables for the yield and recovery of alkaloids from $S$. flavescens Ait.

All experimental data were obtained from a 30-run-experiment by HPLC analysis (as shown in Fig. 9), the yield of total alkaloids 

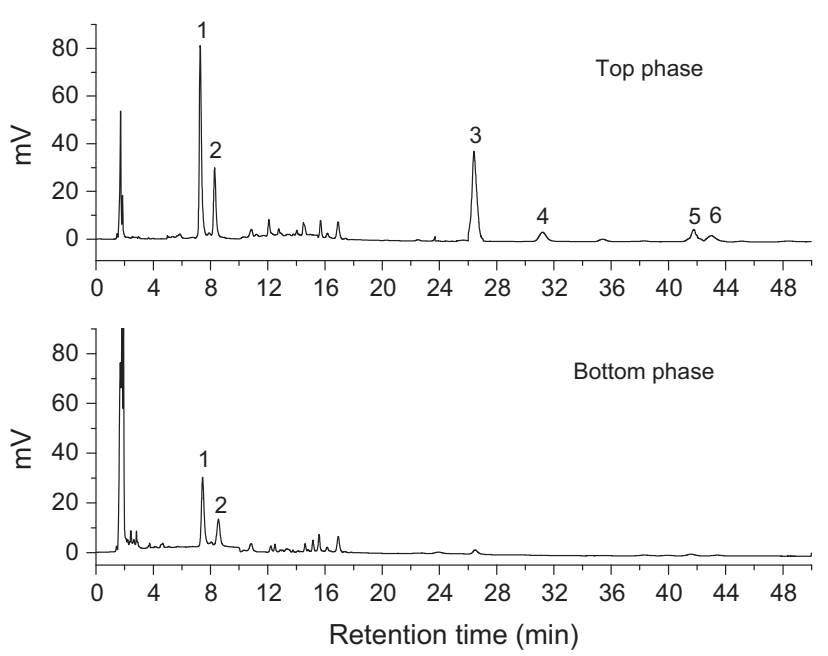

Fig. 9. HPLC chromatograms of the extract of alkaloids from Sophora flavescens Ait by MAATPE: 1 - Oxymatrine; 2 - N-oxysophocarpine; 3 - Sophoridine; 4 - 5-Nmethylcytisine; 5 - Matrine; 6 - Sophocarpine.

ranged from 43.84 to $63.95 \mathrm{mg} / \mathrm{g}$, and the recovery of total alkaloids from $65.37 \%$ to $94.45 \%$. The results were fitted and the values of regression coefficients were calculated by the Design-Expert software version 8.0; the response variable and the test variables are related by the following second-order polynomial equation:

$$
\begin{aligned}
Y(\mathrm{mg} / \mathrm{g})= & 62.01+1.55 X_{1}+0.76 X_{2}+2.68 X_{3}+0.31 X_{4}-0.87 X_{1} X_{2} \\
& +1.00 X_{1} X_{3}-2.42 X_{1} X_{4}-1.02 X_{2} X_{3}-0.13 X_{2} X_{4}-1.48 X_{3} X_{4} \\
& -2.32 X_{1}^{2}-1.36 X_{2}^{2}-1.72 X_{3}^{2}-2.35 X_{4}^{2}\left(R^{2}=0.9336\right)
\end{aligned}
$$

The RSM model expressed in Eq. (5) has a $R^{2}=0.9336$, providing a trustworthy probe into factors and their interactions, which was not possible to identify using the single-factor experiment (Table 5). Among the four variables, $X_{1}, X_{2}, X_{3}$, and $X_{4}$, the linear coefficients $\left(X_{1}, X_{4}\right)$, the interaction coefficient $\left(X_{1} X_{2}\right)$, and the quadratic terms $\left(X_{1}^{2}, X_{2}^{2}, X_{4}^{2}\right)$ were found significant $(p<0.001)$. The single variables, $X_{1}, X_{2}$, and $X_{4}$ were determined as the most important variables for the yield of alkaloids. The composition variables, $X_{1}$, $X_{2}$, interacted with each other. The RSM study was therefore extremely important for the optimization of ATPSs. The other interactions, although less significant in comparison with $X_{1} X_{2}$, were still relatively important and contributed to the yield of alkaloids $(p<0.01)$. The $X_{1} X_{4}$ showed the significance of $X_{4}$, which was highlighted only when the interactions with the compositions were considered. It demonstrated that the extraction temperature, $X_{4}$, was synergistically more interactive with ethanol $\left(X_{1}\right)$ than with salt $\left(X_{2}\right)$, enabling the ethanol purification in MAATPE. $X_{1}, X_{2}$, and $X_{4}$ are the most important variables from the process described above, since both the extraction yield and recovery depend on the composition of ATPS [38-51,28,52-59], followed in significance by the extraction temperature, which was directly related to the heating effect, produced by interaction of microwave with ATPS based on its polarity $[31,32]$. Accordingly, the predicted values for total alkaloids (the yield, $64.39 \mathrm{mg} / \mathrm{g}$ and the recovery, $94.52 \%$ ) were found in a response to our lab validation using $X_{1}=28 \%, X_{2}=18 \%, X_{3}=60: 1$, and $X_{4}=90^{\circ} \mathrm{C}$. It was consistent with the values predicted in Table 6 . Due to the high cost of ethanol and pre-determined scale of the compositions and extraction temperature, no further RSM study was recommended.

\subsection{Mechanisms of MAATPE}

A schematic diagram was drawn, based on the facts and evidences observed in our study of MAATPE. First, Fig. 10(a) showed that the herb powder sample was located in between the salt-rich bottom phase and the ethanol-rich top phase, which was different from conventional extraction. Comparatively, this MAATPE experienced two processes: solid-liquid extraction of alkaloids from the herb matrix into the bottom phase, and a liquid-liquid extraction from the bottom to the top phase (Fig. 10b). In the above process, the salt played two roles in the improvement of demixing and absorbing microwave. Owing to its higher conductivity, the salt solution could facilitate the separation from the miscible ethanol. This had a key part in the bottom phase, where solid-liquid extraction occurred between the herb material and the salt-rich phase. Due to the higher conductivity of the bottom phase, microwave could cause a stronger internal heating and molecular agitation, and thus, facilitated the breakdown of the weak interplay of alkaloids with the matrix and speeded up the removal of the targeted constituents and impurities [31,35,37]. On the contrary, the ethanol top phase, having a lower conductivity, did not contribute much to the solid-liquid extraction. However, it still could act as purification during the liquid-liquid extraction. In MAATPE process, the alkaloids were extracted preferentially from the herb to the bottom phase, and migrated to the top phase for their purification. Thus, among the above multiple phases, the mass-transfer equilibriums of the alkaloids were considered one of the key factors for the improvement of the extraction yield and purification recovery. At a certain high temperature, the liquid-liquid extraction could continuously drive alkaloids from the salt-rich bottom phase into the ethanol-rich top phase; forming an alkaloids enrichment favored equilibrium, which could be further enhanced by microwave agitation.

Second, MAATPE introduced changes in the surface morphologies of the herb samples; Fig. 11 shows the effect of microwave onto the morphologies of the herb matrix. In comparison, the morphologies of herb matrix materials collected after MAATPE, two conventional extraction treatments and non-treated as provided, were observed by scanning electron microscopy (SEM). SEM micrographs illustrated that MAATPE resulted in micro-cracks on the cell surface of the matrix, whereas the conventional extractions exhibited surface shrinkage. This was because the MAAPE could cause cell rupture [59]. In addition of the internal heating, microwave with higher frequency could accelerate the dipole rotation and

\begin{tabular}{|c|c|c|c|c|c|c|c|}
\hline \multicolumn{4}{|l|}{ Yield (mg/g) } & \multicolumn{4}{|l|}{ Recovery (\%) } \\
\hline Determined & RSD (\%) & Mean value ${ }^{a}$ & Predicted & Determined & RSD (\%) & Mean value ${ }^{a}$ & Predicted \\
\hline 64.17 & 0.71 & $63.73 \pm 0.45$ & 64.39 & 92.15 & 0.15 & $92.09 \pm 0.14$ & 94.52 \\
\hline 63.66 & & & & 92.06 & & & \\
\hline 64.10 & & & & 92.31 & & & \\
\hline 63.01 & & & & 91.90 & & & \\
\hline 63.72 & & & & 92.09 & & & \\
\hline 63.31 & & & & 92.02 & & & \\
\hline
\end{tabular}

Table 6

The predicted and experimental results of the responses for alkaloids under optimum conditions.

\footnotetext{
a Mean \pm standard deviation $(n=6)$.
} 


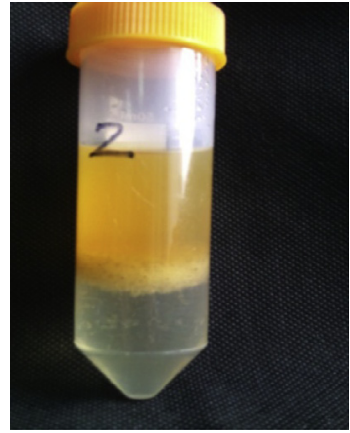

(a)

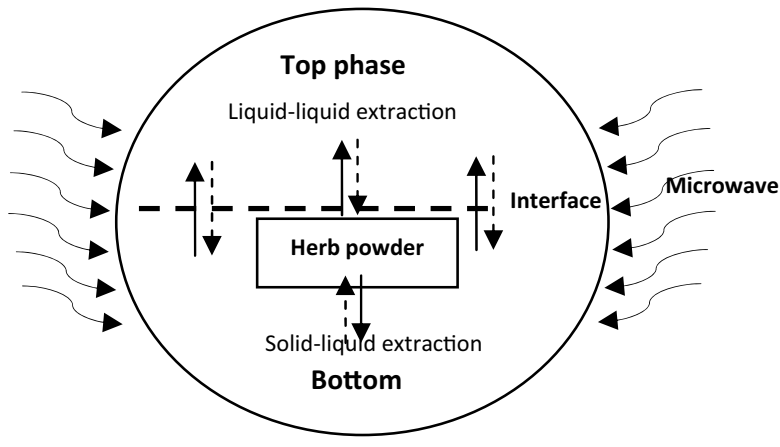

(b)

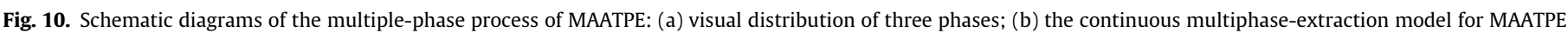
extraction and purification.

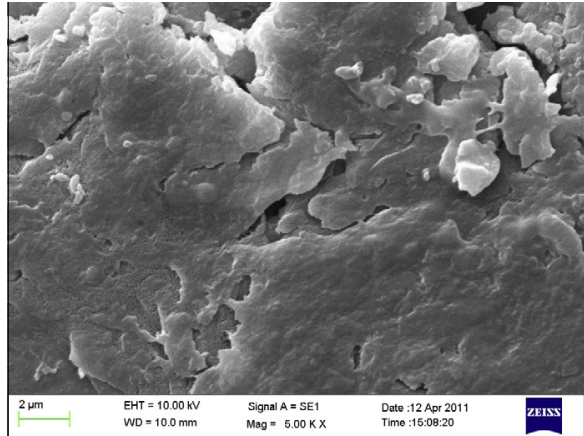

(a)

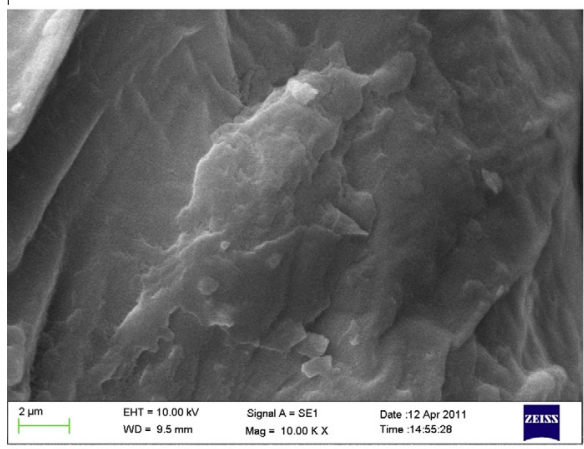

(c)

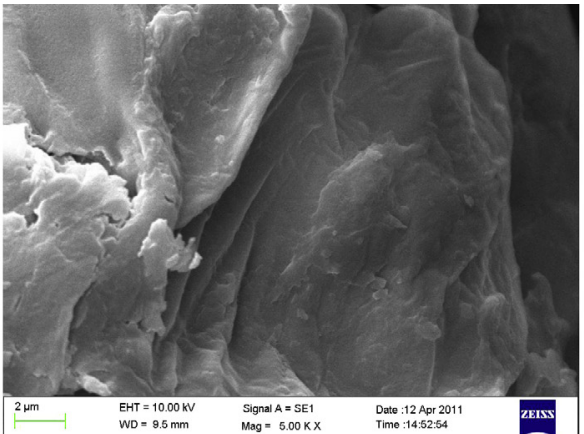

(b)

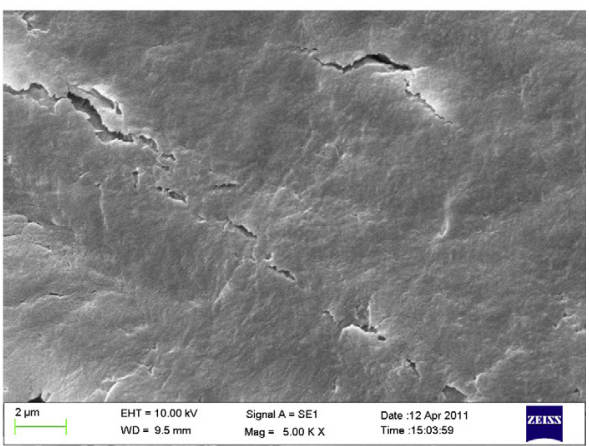

(d)

Fig. 11. The pictures of the herb by electron scanning microscopy: MAATPE (a); heat reflux extraction (b); soaking extraction (c); non-extracted (d).

collision, having a synergistic effect regarding the mechanical disturbance. Additionally, MAATPE also accelerated demixing. Demixing of MAATPE $(45 \mathrm{~s})$ is much faster than the spontaneous demixing of ATPE (1.5 min) [60]. The fast demixing may contribute to a more efficient purification with a higher recovery, especially when the conductivity difference $(\Delta k)$ between two phases is increased, as shown in Table 2 and 3. The demixing effect under the microwave-assisted condition could benefit remarkably sample pretreatment before the quantitative analysis.

\subsection{Comparison of different extraction methods}

In our studies, MAATPE is a relatively new approach. It combines conventional extraction, ATPE and MAE. For validation of MAATPE, a comparative study of the one-step MAATPE with the two-step MAE-ATPE was carried out using ATPS, water/ATPS, and
ethanol/ATPS, respectively. MAATPE was carried out under the RSM optimized conditions, whereas MAE-ATPE followed MAE with ethanol or water before ATPE, according to the recent protocols $[51,28]$. The results in Table 7 show that the one-step MAATPE significantly improved the extraction yield compared to the two-step (single solvent) MAE-ATPE, while the recovery remained the same. As illustrated in Fig. 12, there were 6 alkaloids, named oxymatrine, $\mathrm{N}$-oxysophocarpine, sophoridine, $\mathrm{N}$-methylcytisine (identified by LC-MS), matrine, and sophocarpine in the top phase of the extraction by MAATPE. According to the purities of the extracts, analyzed by HPLC chromatograms, MAATPE yielded an extract with more constituents in a higher content and fewer impurities, whereas MAE-ATPE approaches, using only ethanol, presented somewhat similar results, but with more impurities. MAATPE, combining the extraction and purification in one step, demonstrated the best performance among the three methods as shown in Table 7. Thus, 
Table 7

The results of extracted alkaloids from Sophora flavescens Ait. by different methods.

\begin{tabular}{|c|c|c|c|c|c|c|}
\hline Method & Mode & Extracting solvent & Yield (mg/g) & Relative purity $^{\mathrm{a}}(\%)$ & Recovery (\%) & Relative purity ${ }^{\mathrm{a}}(\%)$ \\
\hline MAE-ATPE 1 & MAE prior to ATPE & Water + ATPS & 20.50 & 30.44 & 91.85 & 70.33 \\
\hline MAE-ATPE 2 & MAE prior to ATPE & Ethanol + ATPS & 53.04 & 40.67 & 89.51 & 56.21 \\
\hline MAATPE & Simultaneously & ATPS & 63.78 & - & 92.09 & 69.54 \\
\hline
\end{tabular}

a The relative purity of total alkaloids is the ratio of the peak area of oxymatrine, N-oxysophocarpine, sophoridine, matrine, and sophocarpine to the total peak area except $\mathrm{N}$-methylcytisine without its standard.

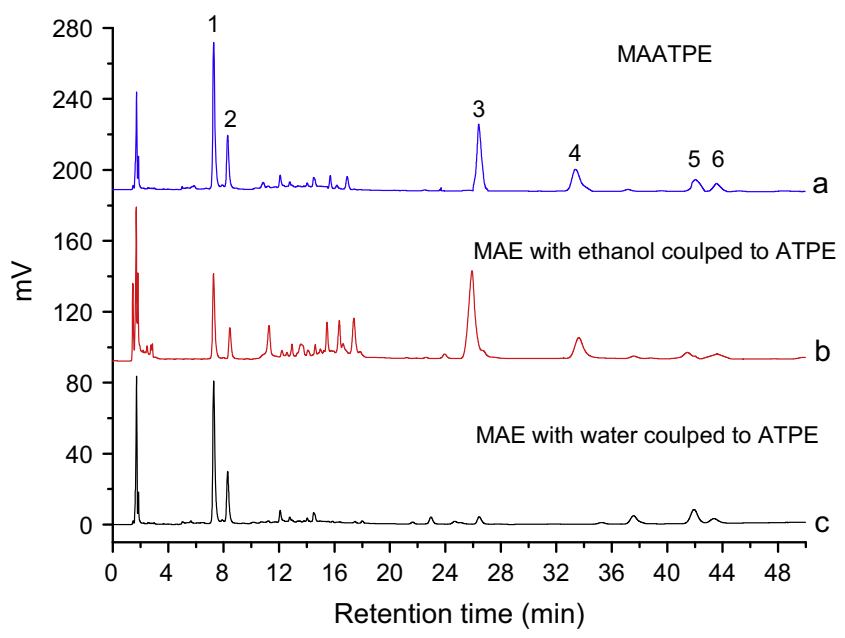

Fig. 12. HPLC chromatograms of the top phases for alkaloids, extracted from Sophora flavescens Ait. by MAATPE with ATPS (a); MAE-ATPE with ethanol (b); and MAE-ATPE with water (c). 1 - Oxymatrine; 2 - N-oxysophocarpine; 3 - Sophoridine; 4 - N-methylcytisine; 5 - Matrine; 6 - Sophocarpine.

MAATPE simplifying experimental procedures can be applied not only in sample pretreatment prior to quantitative analysis but also in the industrial scale-up production.

\section{Conclusions}

In this study, a microwave-assisted aqueous two-phase extraction (MAATPE) was developed for the first time to enhance the yield and recovery of alkaloids from $S$. flavescens Ait. MAATPE, integrating MAE with ATPE into one-step procedure, provided a rapid and effective method for the simultaneous extraction and purification. ATPS of ethanol/ammonium sulfate was carefully selected as multi-function extraction solvent, and assessed by exploring the sophisticated 3D phase diagram. The protocol for MAATPE was screened through the single-factor experiment and optimized by RSM. The optimized conditions improved significantly the yield and recovery of the alkaloids compared with those of the conventional approaches. For a better understanding of MAATPE, we depicted a continuous multiphase model of the conjugated extraction processes. In this model, MAATPE has a significant impact on the solid-liquid extraction that might be involved in the surface and cell rupture of the herb, and in the liquid-liquid purification. The demixing time for phase separation, morphological changes on the herb matrix, and most importantly, the yield of the extract and the recovery of alkaloid, were observed and recorded. Compared to the conventional methods, MAATPE, using the ethanol/ ammonia sulfate system as a multi-function extraction solvent, has the potential of obtaining targeted constituents with a lower extent of impurity. It exhibits a green, rapid, and easy technique for the simultaneous extraction and purification of active constituents in microbial cells or plants.

\section{Acknowledgements}

This work was supported by the Science and Technology Project of Guangzhou (No. 2008Z1-E301) and Faculty Development fund Project of Guangdong Pharmaceutical University (No. 52104109).

\section{References}

[1] Chinese Pharmacopoeia Commission, Kushen (Sophorae Flavescentis Radix), Pharmacopoeia of the People's Republic of China, vol. 1, China Medicine Science and Technology Press, Beijing, 2010, pp. 188-189.

[2] K.L. Miao, J.Z. Zhang, Y. Dong, Y.F. Xi, Research progress on the chemical compounds and pharmacology of Sophora flavescens, Nat. Prod. Res. Dev. 13 (2001) 69-73.

[3] H.Z. Chen, H.Y. Bao, M. Nuo, Y. Ma, Summary of chemical composition and pharmacological effects and clinical study of Sophora flavescens, Ginseng Res. 22 (2010) 31-37.

[4] H.J. Zhao, W.J. Sun, Research progress on the flavonoids in Sophora flavescens Ait. and their pharmacology, J. Chin. Med. Mater. 28 (2005) 247-251.

[5] J.H. Jin, J.S. Kim, S.S. Kang, K.H. Son, H.W. Chang, H.P. Kim, Anti-inflammatory and anti-arthritic activity of total flavonoids of the roots of Sophora flavescens J. Ethnopharmacol. 127 (2010) 589-595.

[6] P.L. Ding, Z.X. Liao, H. Huang, P. Zhou, D.F. Chen, (+)-12aHydroxysophocarpine, a new quinolizidine alkaloid and related anti-HBV alkaloids from Sophora flavescens, Bioorg. Med. Chem. Lett. 16 (2006) 12311235.

[7] John W. Ho, Parry L Ngan. Hon, Wai O. Chim, Effects of oxymatrine from Ku Shen on cancer cells, Anticancer Agents Med. Chem. 9 (2009) 823-826.

[8] Y.P. Yang, X.C. Shen, Research progress of pharmacological effects of oxymatrine, Chin. J. Hosp. Pharm. 29 (2009) 405-407.

[9] M. Huang, Y.Y. Hu, X.Q. Dong, Q.P. Xu, W.H. Yu, Z.Y. Zhang, The protective role of oxymatrine on neuronal cell apoptosis in the hemorrhagic rat brain, J. Ethnopharmacol. 143 (2012) 228-235.

[10] X.Y. Huang, C.X. Chen, Effect of oxymatrine, the active component from Radix Sophorae flavescentis (Kushen), on ventricular remodeling in spontaneously hypertensive rats, Phytomedicine 20 (2013) 202-212.

[11] Y.H. Zhou, H.L. Shan, G.F. Qiao, X.H. Sui, Y.J. Lu, B.F. Yang, Inotropic effects and mechanisms of matrine, a main alkaloid from Sophora flavescens Ait, Biol. Pharm. Bull. 31 (2008) 2057-2062.

[12] L.H. Zhang, B.E. Chen, M.J. Pan, Research progress of pharmacological effects of matrine, Chin. Tradit. Herb. Drugs 40 (6) (2009) 1000-1003.

[13] B. Zhang, Z.Y. Liu, Y.Y. Li, Y. Luo, M.L. Liu, H.Y. Dong, Y.X. Wang, Y. Liu, P.T. Zhao, F.G. Jin, Z.C. Li, Antiinflammatory effects of matrine in LPS-induced acute lung injury in mice, Eur. J. Pharm. Sci. 44 (2011) 573-579.

[14] C.Z. Liang, J.K. Zhang, Z.L. Shi, B. Liu, C.C.Q. Shen, H.M. Tao, Matrine induces caspase-dependent apoptosis in human osteosarcoma cells in vitro and in vivo through the upregulation of Bax and Fas/FasL and downregulation of Bcl-2, Cancer Chemother. Pharmacol. 69 (2012) 317-331.

[15] M. Xu, L. Yang, L.Z. Hong, X.Y. Zhao, H.L. Zhang, Direct protection of neurons and astrocytes by matrine via inhibition of the NF- $\mathrm{BB}$ signaling pathway contributes to neuroprotection against focal cerebral ischemia, Brain Res. 1454 (2012) 48-64.

[16] H.F. Zhang, L.J. Shi, G.Y. Song, Z.G. Cai, C. Wang, R.J. An, Protective effects of matrine against progression of high-fructose diet-induced steatohepatitis by enhancing antioxidant and anti-inflammatory defences involving Nrf2 translocation, Food Chem. Tox. 55 (2013) 70-77.

[17] X. Chen, C.Q. Yi, X.Q. Yang, X.R. Wang, Liquid chromatography of active principles in Sophora flavescens root, J. Chromatogr. B 812 (2004) 149-163.

[18] X.J. Liu, M.A. Cao, W.H. Li, C.S. Shen, S.Q. Yan, C.S. Yuan, Alkaloids from Sophora flavescens Aition, Fitoterapia 81 (2010) 524-527.

[19] G.Q. Liu, J. Dong, H. Wang, Y.K. Hashi, S.Z. Chen, Characterization of alkaloids in Sophora flavescens Ait. by high-performance liquid chromatographyelectrospray ionization tandem mass spectrometry, J. Pharm. Biomed. Anal 54 (2011) 1065-1072.

[20] H.Y. Wang, Y.C. Lu, J. Chen, J.C. Li, S.H. Liu, Subcritical water extraction of alkaloids in Sophora flavescens Ait. and determination by capillary electrophoresis with field-amplified sample stacking, J. Pharm. Biomed. Anal. 58 (2012) 146-151.

[21] J.H. Ruan, J. Liu, D. Zhu, T. Gong, F.M. Yang, X.J. Hao, Z.R. Zhang, Preparation and evaluation of self-nanoemulsified drug delivery systems (SNEDDSs) of matrine 
based on drug-phospholipid complex technique, Int. J. Pharm. 386 (2010) 282-290.

[22] S.W. Yang, L.X. Li, Advances in the research and preparation of matrine in pharmaceutics, Pract. Pharm. Clin. Rem. 15 (2012) 52-54.

[23] F.L. Ma, Y. Cheng, Research progress of pharmacodynamics of matrine in various preparations, Chin. Tradit. Patent Med. 26 (2004) 420-422.

[24] Y. Ma, Q.W. Zhang, Z.M. Wang, H.M. Gao, Advance in study on compound Kushen injection, Chin. J. Exp. Tradit. Med. Form. 18 (2012) 342-345.

[25] L.N. Li, M.S. Ji, Z.Y. Su, Research advances in use of the agricultural fungicide Sophora flavescens, Agrochemicals 45 (2006) 581-583.

[26] M.X. Lu, H.P. Zeng, X.J. Wang, Y. Xie, H. Wang, Recent progress in pesticidal alkaloids, Agrochemicals 43 (2004) 249-253.

[27] X.M. Song, Z.S. Tang, The Extraction and Preparation of Chemical Components of Traditional Chinese Medicine, People's Medical Publishing House, Beijing, 2004. pp. 296-300.

[28] W. Zhang, H.H. Chen, X.Q. Liu, H.J. Fan, X.H. She, S.J. Luo, Comparison of extraction of alkaloids from Sophora flavescens by different microwave assisted methods, Chin. J. Exp. Tradit. Med. Form. 18 (2012) 34-38.

[29] J.Y. Ling, G.Y. Zhang, Z.J. Cui, C.K. Zhang, Supercritical fluid extraction of quinolizidine alkaloids from Sophora flavescens Ait. and purification by highspeed counter-current chromatography, J. Chromatogr. A 1145 (2007) 123127.

[30] W.T. Bi, M.L. Tian, K. Ho, Solid-phase extraction of matrine and oxymatrine from Sophora flavescens Ait using amino-imidazolium polymer, J. Sep. Sci. 33 (2010) 1739-1745.

[31] C.H. Chan, R. Yusoff, G.C. Ngoh, F.W. Kung, Microwave-assisted extractions of active ingredients from plants, J. Chromatogr. A 1218 (2011) 6213-6225.

[32] A. Delazar, L. Nahar, S. Hamedeyazdan, S.D. Sarker, Microwave-assisted extraction in natural products isolation, Methods Mol. Biol. 864 (2012) 89115.

[33] B.K. Tang, W.T. Bi, M.L. Tian, K.H. Row, Application of ionic liquid for extraction and separation of bioactive compounds from plants, J. Chromatogr. B 904 (2012) 1-21.

[34] Z.F. Wei, Y.G. Zu, Y.J. Fu, W. Wang, M. Luo, C.J. Zhao, Y.Z. Pan, Ionic liquidsbased microwave-assisted extraction of active components from pigeon pea leaves for quantitative analysis, Sep. Purif. Technol. 102 (2013) 75-81.

[35] J.R.J. Paré, J.M.R. Bélanger, S.S. Stafford, Microwave-assisted process (MAPTM): new tool for the analytical laboratory, TrAC, Trends Anal. Chem. 13 (1994) $176-184$.

[36] C.S. Eskilsson, E. Björklund, Analytical-scale microwave-assisted extraction, J. Chromatogr. A 902 (2000) 227-250.

[37] B. Kaufmann, P. Christen, Recent extraction techniques for natural products: microwave-assisted extraction and pressurised solvent extraction, Phytochem. Anal. 13 (2002) 105-113.

[38] P.A. Albertson, Partition of cell particles and macromolecules, third ed., Wiley, New York, 1986.

[39] M.R. Kula, Trends and future prospects of aqueous two-phase extraction, Bioseparation 1 (1990) 181-189.

[40] A.D. Diamond, J.T. Hsu, Aqueous two-phase systems for biomolecule separation, Adv. Biochem. Eng. Biotechnol. 47 (1992) 89-135.

[41] O. Aguilar, M. Rito-Palomares, Aqueous two-phase systems strategies for the recovery and characterization of biological products from plants, J. Sci. Food Agric. 90 (2010) 1385-1392.

[42] P.A. Rosa, A.M. Azevedo, S. Sommerfeld, W. Bäcker, M.R. Aires-Barros, Aqueous two-phase extraction as a platform in the biomanufacturing industry: economical and environmental sustainability, Biotechnol. Adv. 29 (2011) 559-567.
[43] F. Ruiz-Ruiz, J. Benavides, O. Aguilar, M. Rito-Palomares, Aqueous two-phase affinity partitioning systems: current applications and trends, J. Chromatogr. A 1244 (2012) 1-13.

[44] Z.L. Xiu, A.P. Zeng, Present state and perspective of downstream processing of biologically produced 1,3-propanediol and 2,3-butanediol, Appl. Microbiol. Biotechnol. 76 (2008) 917-926.

[45] Z.G. Li, H. Teng, Z.L. Xiu, Aqueous two-phase extraction of 2,3-butanediol from fermentation broths using an ethanol/ammonium sulfate system, Proc. Biochem. 45 (2010) 731-737.

[46] Z.G. Li, H. Teng, Z.L. Xiu, Extraction of 1,3-propanediol from glycerol-based fermentation broths with methanol/phosphate aqueous two-phase system, Proc. Biochem. 46 (2011) 586-591.

[47] Y.X. Guo, J. Han, D.Y. Zhang, L.H. Wang, L.L. Zhou, An ammonium sulfate/ ethanol aqueous two-phase system combined with ultrasonication for the separation and purification of lithospermic acid B from Salvia miltiorrhiza Bunge, Ultrason. Sonochem. 19 (2012) 719-724.

[48] X. Liu, T. Mu, H. Sun, M. Zhang, J. Chen, Optimisation of aqueous two-phase extraction of anthocyanins from purple sweet potatoes by response surface methodology, Food Chem. 141 (2013) 3034-3041.

[49] Z.J. Tan, F.F. Li, X.L. Xu, Extraction and purification of anthraquinones derivatives from Aloe vera L. using alcohol/salt aqueous two-phase system, Bioproc. Biosys. Eng. 36 (2013) 1105-1113.

[50] Y.X. Guo, J. Han, D.Y. Zhang, L.H. Wang, L.L. Zhou, Aqueous two-phase system coupled with ultrasound for the extraction of lignans from seeds of Schisandra chinensis (turcz.) Baill, Ultrason. Sonochem. 20 (2013) 125-132.

[51] X.Q. Liu, H.J. Fan, X.W. Huang, L.F. Zhang, HPLC determination of 5 alkaloids in Sophora flavescens Ait with microwave-assisted extraction, PTCA (Part B: Chem. Anal.) 48 (2012) 299-302.

[52] X.Q. Liu, W. Zhang, H.J. Fan, L.P. Wang, X.W. Huang, Y. Feng, D. Zhu, Separation of alkaloids in Sophora flavescens Ait. by aqueous two-phase extraction, Chin. J. Proc. Eng. 12 (2012) 641-647.

[53] H. Wang, Y.S. Dong, Z.L. Xiu, Microwave-assisted aqueous two-phase extraction of piceid, resveratrol and emodin from Polygonum cuspidatum by ethanol/ammonium sulphate systems, Biotechnol. Lett. 30 (2008) 2079-2084.

[54] L. Liu, Y.S. Dong, Z.L. Xiu, Three-liquid-phase extraction of diosgenin and steroidal saponins from fermentation of Dioscorea zingibernsis $\mathrm{CH}$ Wright, Proc. Biochem. 45 (2010) 752-756.

[55] X. Lin, Y.Z. Wang, X.J. Liu, S.Y. Huang, Q. Zeng, ILs-based microwave-assisted extraction coupled with aqueous two-phase for the extraction of useful compounds from Chinese medicine, Analyst 137 (2012) 4076-4085.

[56] D.Y. Zhang, Y.G. Zu, Y.J. Fu, W. Wang, L. Zhang, M. Luo, F.S. Mu, X.H. Yao, M.H. Duan, Aqueous two-phase extraction and enrichment of two main flavonoids from pigeon pea roots and the antioxidant activity, Sep. Purif. Technol. 102 (2013) 26-33.

[57] F.Y. Ma, C.B. Gu, C.Y. Li, M. Luo, W. Wang, Y.G. Zu, J. Li, Y.J. Fu, Microwaveassisted aqueous two-phase extraction of isoflavonoids from Dalbergia odorifera T. Chen leaves, Sep. Purif. Technol. 115 (2013) 136-144.

[58] G.Z. Pan, F. Li, J. Li, Effect of converter of matrine and oxymatrine on extraction method of Radix Sophorae flavescentis, Res. Pract. Chin. Med. 2 (2008) 52-54.

[59] H.J. Fan, G.X. Lin, X.X. Xiao, G.K. Li, Investigation of thermodynamic mechanism for extraction of active constituents in Lycoris radiata and Rhizma Polygoni Cuspidati using microwave-assisted extraction, Chem. J. Chin. Univ. 27 (2006) 2271-2276.

[60] N. Nagaraj, A.V. Narayan, N.D. Srinivas, K.S.M.S. Raghavarao, Microwave-fieldassisted enhanced demixing of aqueous two-phase systems, Anal. Biochem. 312 (2003) 134-140. 